\title{
Intergenerational welfare effects of a tariff under monopolistic competition
}

\author{
Leon J.H. Bettendorf* \\ OCFEB
}

\author{
Ben J. Heijdra ${ }^{\sharp}$ \\ University of Groningen and OCFEB
}

June 2000

\begin{abstract}
A dynamic overlapping-generations model of a semi-small open economy with monopolistic competition in the goods market is constructed. A tariff increase reduces real output and employment and improves the terms of trade, both in the impact period and in the new steady state. The tariff shock has significant intergenerational distribution effects which are different for creditor and debtor nations. Bond policy neutralizes the intergenerational inequities and allows the computation of first-best and second-best optimal tariff rates. The first-best tariff exploits national market power, but the second-best tariff contains a correction to account for the existence of a potentially suboptimal product subsidy. JEL codes: E20, F12, L16, H23. Keywords: monopolistic competition, love of variety, returns to scale, international trade, industrial policy, intergenerational welfare effects.
\end{abstract}

\section{Introduction}

The desirability of industrial policy in an economy with increasing returns to scale industries has been on and off the research agenda's of both academic economists and policy practitioners at least since the debate in the 1920s between Frank Graham and Frank Knight (see Flam and Helpman (1987) for references). With the advent of the so-called New Trade Theory (Krugman, 1990), the debate has been given a new lease of life. At least two approaches can be distinguished in the recent literature. The first approach, which is mentioned but not pursued in this paper, is better known under the name of 'strategic trade policy.' In this branch of literature, the issue of industrial policy is studied in a setting of large duopolistic or

*OCFEB, Erasmus University, P.O. Box 1738, 3000 DR Rotterdam, The Netherlands. Phone: +31-10-4081808. Fax: +31-10-408-9173. E-mail: bettendorf@few.eur.nl.

${ }^{\sharp}$ Department of Economics, University of Groningen, P.O. Box 800, 9700 AV Groningen, The Netherlands. Phone: +31-50-363-7303, Fax: +31-50-363-7207, E-mail: b.j.heijdra@eco.rug.nl. We thank two anonymous referees for helpful comments on an earlier draft. 
oligopolistic firms battling for market share in the international economy (see Brander (1995) for an overview and references).

The second approach studies the issue of industrial policy in a world characterized by monopolistic competition. In such a setting there is no strategic interaction between firms, and trade in varieties of a differentiated product takes place between countries. Flam and Helpman (1987), for example, construct a static model of a small open economy with a monopolistically competitive production sector. They use the model to study the effects on allocation and welfare of tariffs, export subsidies, $R \& D$ subsidies, and output subsidies. Flam and Helpman (1987, pp. 90-91) identify three mechanisms by which welfare of domestic agents is increased in a monopolistically competitive setting. First, an increase in the number of domestic product varieties expands the range of choice by domestic consumers, who are better off as a result provided they exhibit a preference for diversity. Second, a policy that increases the home price of domestically produced varieties has a positive terms of trade effect which increases welfare of domestic residents. Third, an increase in the output level per domestic firm constitutes a 'pro-competitive' effect and thus increases welfare.

Our paper is a contribution to the second approach to industrial policy. Attention is restricted to the import tariff. In the static model of Flam and Helpman, the introduction of a tariff increases profits which prompts an increase in the number of domestic firms and raises the prices charged by domestic firms. The effects on output per firm is ambiguous, but the terms of trade and welfare of domestic residents both improve as a result (1987, pp. 91-92). Our first objective in this paper is to further study the precise conditions under which an import tariff is welfare-improving. Whilst we retain some of the modelling devices of Flam and Helpman (1987), we modify the analysis in several directions.

One of our modifications is motivated by a recent body of literature in which it has been shown that the conclusions based on static models can be highly misleading because the element of time is missing in such models. In a world populated with infinitely-lived 'representative' agents, this is perhaps not such a problem, because the timing only affects 'when' (but not 'whether') the agents bears the costs of, or receives the benefits from, a particular policy measure. In a world with finitely-lived overlapping generations, however, the timing of the benefits and costs associated with a particular policy becomes vital. In such a setting a policy measure typically affects both existing and future generations differently, i.e. there are not only efficiency but also intergenerational distribution effects that must be considered (cf. Kotlikoff and Summers, 1987).

The importance of intergenerational distribution effects in determining 'optimal' policy has been demonstrated in a small but growing number of papers on very diverse topics. ${ }^{1}$

\footnotetext{
${ }^{1}$ Recent examples include Bovenberg (1993, 1994) on, respectively, investment stimulation and capital taxation, and Engel and Kletzer (1990) and Galor (1994) on tariffs. All these papers analyse a small open economy with perfect competition. Bovenberg and Heijdra (1998) analyse environmental taxes in a closed economy. Broer and Heijdra (forthcoming) study the investment tax credit in a closed economy with monopolistic compe-
} 
The second major objective of our paper is therefore to study the import tariff in a dynamic overlapping-generations economy. We use the perpetual youth approach of Blanchard (1985), but extend it to an open economy and endogenize the labour supply decision of households. Domestic households purchase domestic and foreign products and use the current account in order to smooth their consumption profiles. The country is semi-small, i.e. it is small in world financial markets (and thus faces perfect capital mobility) but it can affect its terms of trade (see Buiter (1987)). There are many small domestic firms producing varieties that are sold at home and abroad. Free exit/entry eliminates excess profits and determines the equilibrium number of firms in the domestic economy. Increasing returns to scale exist because an increase in the number of product varieties boosts the productivity of the variable labour input.

The analysis yields a number of conclusions. First, like Sen and Turnovsky (1989) but unlike Flam and Helpman (1987), we find that an increase in the tariff reduces output and employment, both in the short run and in the long run. In our model the tariff shock prompts a negative labour supply response which leads to a reduction in the number of firms. Like Flam and Helpman (1987), we find that the real exchange rate appreciates both at impact and in the long run.

Second, when the tariff revenue is rebated to households in the form of age-independent transfers, then the import tariff affects generations unequally. Intuitively, such lump-sum transfers are not generationally neutral in utility terms because asset holdings differ across generations. Third, the intergenerational welfare effects of a tariff depend critically on whether the country's residents are relatively patient (creditor country) or impatient (debtor country). Fourth, by accompanying the tariff increase by a suitable bond policy, the tariff revenue can be rebated in an age-dependent fashion so that the intergenerational redistributional effects can be neutralized and only the pure efficiency effects remain. In such an egalitarian setting it is possible to study the optimal tariff. It is shown that the optimal tariff depends not only on 'national market power' (as in Gros (1987)) but also on the pre-existing domestic distortion of monopolistic competition. To the extent that the policy maker has no instrument to combat the domestic monopoly distortion (such as a product subsidy), the second-best optimum tariff is reduced vis-à-vis its first-best value. Intuitively, output is already too low due to the domestic monopoly distortion and increasing the tariff only exacerbates this problem. In the absence of a domestic distortion and/or if the product subsidy is set optimally, the first-best tariff is aimed at exploiting national market power to the fullest extent possible. Our model thus yields precise and intuitively understandable prescriptions about the interaction between the optimum tariff and pre-existing domestic distortions. We thus extend the seminal work by Johnson $(1965)$ and Bhagwati $(1967,1971)$ on instrument targeting to a dynamic setting of overlapping generations and monopolistic competition.

The remainder of the paper proceeds as follows. In section 2 the model of a semi-small

tition. Bettendorf and Heijdra (forthcoming) study the macroeconomic and distributional effects of a product subsidy in an open economy. See also the recent study by Keuschnigg and Kohler (1996). 
open economy is developed. In section 3 the macroeconomic allocation effects of an import tariff are studied, both at impact, during transition, and in the long run. Section 4 constitutes the core of our paper and is dedicated to the welfare analysis both without and with bond policy. Finally, section 5 contains some concluding remarks.

\section{The model}

\subsection{Households}

The basic model of household behaviour builds on the work of Blanchard (1985) and its extension to the open economy by Giovannini (1988). Beside the endogeneity of labour supply, the main difference with these two models is the introduction of a diversified consumption good into the utility function of the agents. This in turn opens the scope for imperfectly competitive behaviour on the part of producers, which forms the major innovation of this paper.

In this model there is a fixed population of agents each facing a given constant probability of death. During their entire life agents have a time endowment of unity which they allocate over labour and leisure. ${ }^{2}$ The utility functional at time $t$ of the representative agent born at time $v$ is denoted by $\Lambda(v, t)$ and has the following form:

$$
\Lambda(v, t) \equiv \int_{t}^{\infty} \log U(v, \tau) \mathrm{e}^{(\alpha+\beta)(t-\tau)} d \tau
$$

where $\alpha$ is the pure rate of time preference $(\alpha>0), \beta$ is the probability of death $(\beta \geq 0)$, and $U(v, \tau)$ is sub-utility which depends on leisure $(1-L(v, \tau))$ and consumption of domestic and foreign goods $(C(v, \tau)$ and $Z(v, \tau)$, respectively):

$$
U(v, \tau) \equiv\left[C(v, \tau)^{\delta} Z(v, \tau)^{1-\delta}\right]^{\gamma}[1-L(v, \tau)]^{1-\gamma},
$$

with $0<\gamma \leq 1$ and $0<\delta<1 .^{3}$

The domestic economy consists of imperfectly competitive firms that each produce a single variety of a diversified good. These goods are close but imperfect substitutes in consumption. Following Spence (1976) and Dixit and Stiglitz (1977) the diversified goods can be aggregated over existing varieties $(1,2, . ., N(\tau))$ in order to obtain $C(v, \tau)$ :

$$
C(v, \tau) \equiv\left[\sum_{i=1}^{N(\tau)} C_{i}(v, \tau)^{1 / \eta}\right]^{\eta}, \quad \eta \geq 1,
$$

\footnotetext{
${ }^{2}$ Sen and Turnovsky (1989, p. 827) likewise stress the importance of an endogenous labour supply response. Their representative-agent model assumes perfect competition and studies the effects of a tariff on capital accumulation. Gavin (1991) abstracts from capital accumulation and studies intersectoral reallocation due to tariff changes.

${ }^{3}$ Hence, it is assumed that the Armington substitution elasticity between domestic and foreign consumption goods equals unity. This assumption is made for simplicity. A non-unitary Armington elasticity does not substantially affect the arguments in this paper.
} 
where $C_{i}(v, \tau)$ is the consumption of domestically produced variety $i$ in period $\tau$ by an agent born in period $v(\leq \tau)$. The parameter $\eta$ regulates both the preference for diversity (PFD) effect and the size of the monopoly markup (Bénassy, 1996, 1998). The true price deflator corresponding to (3) is:

$$
P(\tau) \equiv\left[\sum_{i=1}^{N(\tau)} P_{i}(\tau)^{1 /(1-\eta)}\right]^{1-\eta},
$$

where $P_{i}(\tau)$ is the price of variety $i$. The homogeneous imported consumption good is used as the numeraire and features a given world price $\left(P_{Z}(\tau)=1\right){ }^{4}$ Hence, $P(\tau)$ represents the terms of trade, i.e. the relative price of exports in terms of imports.

The agent's budget identity, expressed in terms of the foreign good, is equal to:

$$
\dot{A}(v, \tau)=(r+\beta) A(v, \tau)+W(\tau) L(v, \tau)-T(\tau)-P(\tau) C(v, \tau)-\left(1+t_{M}\right) Z(v, \tau),
$$

where $\dot{A}(v, \tau) \equiv d A(v, \tau) / d \tau, r$ is the fixed world real rate of interest, ${ }^{5} W(\tau)$ is the real wage rate (assumed age-independent for convenience), $T(\tau)$ are net lump-sum taxes, $t_{M}$ is an $a d$ valorem import tariff, and $A(v, \tau)$ are real tangible assets. All tangible assets are perfect substitutes:

$$
A(v, \tau) \equiv B(v, \tau)+F(v, \tau)
$$

where $B(v, \tau)$ and $F(v, \tau)$ are, respectively, government bonds and net foreign assets, both measured in terms of the foreign good. We define full expenditure $X(v, \tau)$ as the sum of spending on domestic and foreign consumption goods and on leisure, i.e.:

$$
X(v, \tau) \equiv P(\tau) C(v, \tau)+\left(1+t_{M}\right) Z(v, \tau)+W(\tau)[1-L(v, \tau)] .
$$

Due to the separable structure of preferences, the choice problem for the representative agent can be solved in two steps. First, the dynamic problem is solved. This leads to an optimal time profile for full expenditure which is described by the agent's Euler equation:

$$
\frac{\dot{X}(v, \tau)}{X(v, \tau)}=r-\alpha
$$

In the second step full expenditure is optimally allocated over its component parts:

$$
\begin{aligned}
P(\tau) C(v, \tau) & =\gamma \delta X(v, \tau), \\
\left(1+t_{M}\right) Z(v, \tau) & =\gamma(1-\delta) X(v, \tau), \\
W(\tau)[1-L(v, \tau)] & =(1-\gamma) X(v, \tau),
\end{aligned}
$$

\footnotetext{
${ }^{4}$ Bettendorf and Heijdra (forthcoming) model the foreign good as a differentiated commodity. Since we assume that the domestic economy has no influence on the number of foreign varieties or on their price, our approach entails no loss of generality.

${ }^{5}$ We assume that the domestic economy is small in world capital markets so that it faces a given world real rate of interest $r$.
} 
where $\delta$ thus represents the (constant) share of total goods consumption that is spent on domestic goods and $1-\gamma$ is the spending share of leisure in full expenditure. ${ }^{6}$ Demand for the different varieties of the domestically produced goods is given by:

$$
\frac{C_{i}(v, \tau)}{C(v, \tau)}=\left(\frac{P_{i}(\tau)}{P(\tau)}\right)^{-\eta /(\eta-1)} .
$$

A crucial feature of the Blanchard (1985) model (and all models deriving from it) is its simple demographic structure, which enables the aggregation over all currently alive households. Assuming that at each instance a large cohort of size $\beta S$ is born and that $\beta S$ agents die, and normalising $S$ to unity, the size of the population is constant and equal to unity and the aggregated variables can be calculated as the weighted sum of the values for the different generations. For example, aggregate financial wealth is calculated as $A(\tau) \equiv \int_{-\infty}^{\tau} \beta A(v, \tau) \mathrm{e}^{\beta(v-\tau)} d v$. The aggregated values for the other variables can be obtained in the same fashion. The main equations describing the behaviour of the aggregated household sector are given (for period t) by equations (T1.1) and (T1.5)-(T1.7) in Table 1. Equation (T1.1) is the aggregate Euler equation modified for the existence of overlapping generations of finitely-lived agents. It has the same form as the Euler equation for individual households (equation (8)) except for the correction term due to the distributional effects caused by the turnover of generations. Optimal full expenditure growth is the same for all generations but older generations have a different full expenditure level than younger generations. The correction term appearing in (T1.1) thus represents the difference in average full expenditure and full expenditure by newborns: ${ }^{7}$

$$
\frac{\dot{X}(\tau)}{X(\tau)}=r-\alpha-\beta(\alpha+\beta)\left(\frac{A(\tau)}{X(\tau)}\right)=\frac{\dot{X}(v, \tau)}{X(v, \tau)}-\beta\left(\frac{X(\tau)-X(\tau, \tau)}{X(\tau)}\right),
$$

where $A(\tau) \equiv F(\tau)+B(\tau)$ is aggregate financial wealth. Throughout the paper we analyze the case in which there is no government debt in the initial steady state $(B=0)$. Equation (T1.1) shows that steady-state net foreign assets are positive (negative) if the world interest rate exceeds (falls short of) the rate of time preference, i.e. $F \gtrless 0$ for $r \gtrless \alpha$. Intuitively, net foreign assets are strictly positive (negative) for a patient (impatient) country. The rising (falling) full expenditure profile that this implies ensures that financial wealth is transferredvia the life-insurance companies-from old to young (young to old) generations in the steadystate (see Blanchard, 1985). In the knife-edge case, for which $r=\alpha$, households neither save nor dissave, full expenditure is the same for all generations and steady-state net foreign assets are zero.

\footnotetext{
${ }^{6}$ If $\gamma=1$, labour supply is exogenous and each agent inelastically supplies one unit of labour.

${ }^{7}$ We use the fact that $X(\tau)=(\alpha+\beta)[A(\tau)+H(\tau)], X(\tau, \tau)=(\alpha+\beta)[A(v, \tau)+H(\tau)]$, and $A(\tau, \tau)=0$ in the second step, where $H(t)$ is human wealth, i.e. the after-tax present value of the household's time endowment: $H(t) \equiv \int_{t}^{\infty}[W(\tau)-T(\tau)] \exp [(r+\beta)(t-\tau)] d \tau$.
} 


\section{Table 1: Short-run version of the model}

$$
\begin{aligned}
\dot{X}(t) & =(r-\alpha) X(t)-\beta(\alpha+\beta)[F(t)+B(t)] \\
\dot{F}(t) & =r F(t)+T B(t) \\
W(t) L(t) & =\left(1+s_{P}\right) Y(t) \\
Y(t) & =P(t)\left[C(t)+E_{0} P(t)^{-\sigma_{T}}\right] \\
P(t) C(t) & =\gamma \delta X(t) \\
\left(1+t_{M}\right) Z(t) & =\gamma(1-\delta) X(t) \\
W(t)[1-L(t)] & =(1-\gamma) X(t) \\
Y(t) / P(t) & =\Omega_{0} L(t)^{\eta} \\
T B(t) & =E_{0} P(t)^{1-\sigma_{T}}-Z(t)
\end{aligned}
$$

Notes:

(a) The homogeneous foreign good is the numeraire. $P(t)$ is the terms of trade.

(b) $\Omega_{0} \equiv k^{-1} \eta^{-\eta}((\eta-1) / f)^{\eta-1}>0$.

\section{$2.2 \quad$ Foreign sector}

The domestic economy has links with the rest of the world through the goods market (via imports of the foreign good and exports of differentiated products) and through the assets market (domestic households can hold foreign assets in their portfolios). Since it is assumed that the domestic economy is small relative to the rest of the world, domestic variables have no impact on foreign macroeconomic variables. Hence, the export equation contains mainly exogenous variables. For simplicity the following specification is adopted for the export demand equation:

$$
[P(\tau)]^{\sigma_{T}}\left(\frac{E_{i}(\tau)}{E_{0}}\right)=\left(\frac{P_{i}(\tau)}{P(\tau)}\right)^{-\eta /(\eta-1)}, \sigma_{T} \geq 1,
$$

where $E_{0}$ is the exogenous component of export demand. In (12), the term $\eta /(\eta-1)$ summarizes how well domestically produced varieties can be substituted by the buyers in the rest of the world. There is also a separate effect of the terms of trade on aggregate exports which is parameterised by $\sigma_{T}$.

The change in net foreign assets is equal to the current account. Since net foreign assets, $F(\tau)$, are measured in terms of foreign goods, the balance of payments equation can be expressed (for period $t$ ) as in equation (T1.2) in Table 1. The first term on the right-hand side is foreign capital income and the second term is the trade balance. 


\section{$2.3 \quad$ Firms}

The domestic economy consists of a single sector characterized by monopolistic competition. Each firm in this sector faces a demand for its product from two sources, i.e. consumption demand from the households sector (represented by $C_{i}(\tau)$ which is obtained by aggregating (10)), and the demand from the rest of the world (given by $E_{i}(\tau)$ in (12)). There are $N(\tau)$ identical domestic firms that each produce one variety of the differentiated product. Labour is the only productive input and technology features increasing returns to scale at the firm level:

$$
L_{i}(\tau)=k Y_{i}(\tau)+f
$$

where $L_{i}(\tau)$ is labour input, $Y_{i}(\tau)$ is marketable output, $f$ is fixed cost modelled in the form of "overhead labour" $(f>0)$, and $1 / k$ is the marginal product of labour. Representative firm $i$ 's profit is defined by:

$$
\Pi_{i}(\tau) \equiv\left(1+s_{P}\right) P_{i}(\tau) Y_{i}(\tau)-W(\tau) L_{i}(\tau)
$$

where $s_{P}$ is an ad valorem subsidy on production. ${ }^{8}$ The firm chooses its output and price in order to maximize (14) subject to the demand restriction $Y_{i}(\tau)=C_{i}(\tau)+E_{i}(\tau)$ and technology (13). This static decision problem yields the familiar pricing rule:

$$
P_{i}(\tau)=\frac{\eta k W(\tau)}{1+s_{P}}
$$

where $\eta>1$ is the markup. In this paper the assumption of Chamberlinian monopolistic competition is made: competitors' reactions are deemed to be absent and entry/exit is assumed to occur until each active firm makes zero excess profit; the well-known tangency solution. By using (13) and (15) in (14) we deduce that $\Pi_{i}(\tau)=W(\tau)\left[(\eta-1) k Y_{i}(\tau)-f\right]$ so that the zero profit condition pins down a constant firm size:

$$
Y_{i}(\tau)=\bar{Y} \equiv \frac{f}{(\eta-1) k}
$$

\subsection{Government}

The government sector is modelled in a very simple fashion. We abstract from macro features of government behaviour such as government spending on goods and services, and distortionary taxes on labour income. The periodic budget identity of the government is:

$$
\dot{B}(\tau)=r B(\tau)+s_{P} Y(\tau)-t_{M} Z(\tau)-T(\tau),
$$

\footnotetext{
${ }^{8}$ We include a pre-existing product subsidy to capture the notion that the policy maker may be engaged in industrial policy aimed at correcting for the monopoly distortions in the economy. Below we demonstrate the interaction between the optimal tariff and the pre-existing product subsidy. In Bettendorf and Heijdra (forthcoming) we study the allocation and welfare effects of the product subsidy.
} 
where $Y(\tau)$ is national income in terms of the foreign good:

$$
Y(\tau) \equiv \sum_{i=1}^{N(\tau)} P_{i}(\tau) Y_{i}(\tau) .
$$

Since the government is expected to remain solvent, the following NPG condition is relevant: $\lim _{\tau \rightarrow \infty} B(\tau) \exp [r(t-\tau)]=0$. The government's budget restriction is obtained by integrating (17) forward subject to this NPG condition:

$$
B(t)=\int_{t}^{\infty}\left[T(\tau)+t_{M} Z(\tau)-s_{P} Y(\tau)\right] \mathrm{e}^{r(t-\tau)} d \tau
$$

\subsection{Equilibrium and stability}

The model is symmetric and can thus be expressed in aggregate terms. All active domestic firms produce the same (constant) amount of output $\left(Y_{i}=\bar{Y}\right.$-see (16)), have the same markup, face the same input prices and thus charge the same price $\left(P_{i}=\bar{P}\right)$ and hire the same amounts of labour $\left(L_{i}=\bar{L}\right.$ ). As a consequence we have $C_{i}=\bar{C}$ and $E_{i}=\bar{E}$ (for $i=1,2, . ., N)$.

The complete dynamic model is given in aggregated form in Table 1. The dynamic part of the model is given by equations (T1.1)-(T1.2). The movement of full expenditure (T1.1) and the balance of payments equation (T1.2) have all been discussed above. The static part of the model is given by equations (T1.3)-(T1.9). Equation (T1.3) is the aggregate demand for labour, and (T1.4) is the equilibrium condition for the domestic market for differentiated goods, written in aggregate form. Equations (T1.5)-(T1.6) are, respectively, consumption of the domestic composite good and the foreign good, and (T1.7) is labour supply. The aggregate production function for the differentiated goods sector is given in (T1.8). It is the aggregated version of (13), where use has been made of the zero pure profit condition. ${ }^{9}$ Finally, (T1.9) is the trade balance, i.e. the difference between export earnings and imports.

The dynamical properties of the model can be illustrated with the aid of Figure 1. As in Blanchard (1985, pp. 230-1) the slope of the $\dot{X}=0$ line depends on the rate of time preference relative to the world interest rate. Since we assume that government debt is zero initially, it follows from (T1.1) that the $\dot{X}=0$ line goes through the origin and is upward (downward) sloping for a creditor (debtor) nation. (In the knife-edge case, for which $r=\alpha$ the $\dot{X}=0$ line coincides with the vertical axis.) For points to the left (right) of the $\dot{X}=0$ line full expenditure rises (falls), as is indicated with vertical arrows.

\footnotetext{
${ }^{9}$ Equation (T1.8) is obtained as follows. In the symmetric equilibrium, $Y_{i}=\bar{Y}$ and $P_{i}=\bar{P}$ so that $Y=$ $N \bar{P} \bar{Y}$. Equation (4) implies $P=N^{1-\eta} \bar{P}$ so that $Y / P=N^{\eta} \bar{Y}$. Furthermore, (13) and the zero profit condition imply that $k \bar{Y}+f=\bar{L}=\eta k \bar{Y}$. Aggregation over all active firms yields $N \bar{Y}=L /(\eta k)$, where $L=N \bar{L}$ is aggregate labour supply. By combining these results we obtain $Y / P=\Omega_{0} L^{\eta}$ and $N=L /(\eta k \bar{Y})$. Preference for diversity thus causes aggregate output and the equilibrium number of firms to exhibit, respectively, increasing and constant returns to factor supplies. See Heijdra and Van der Ploeg (1996) and Heijdra (1998) for further details.
} 


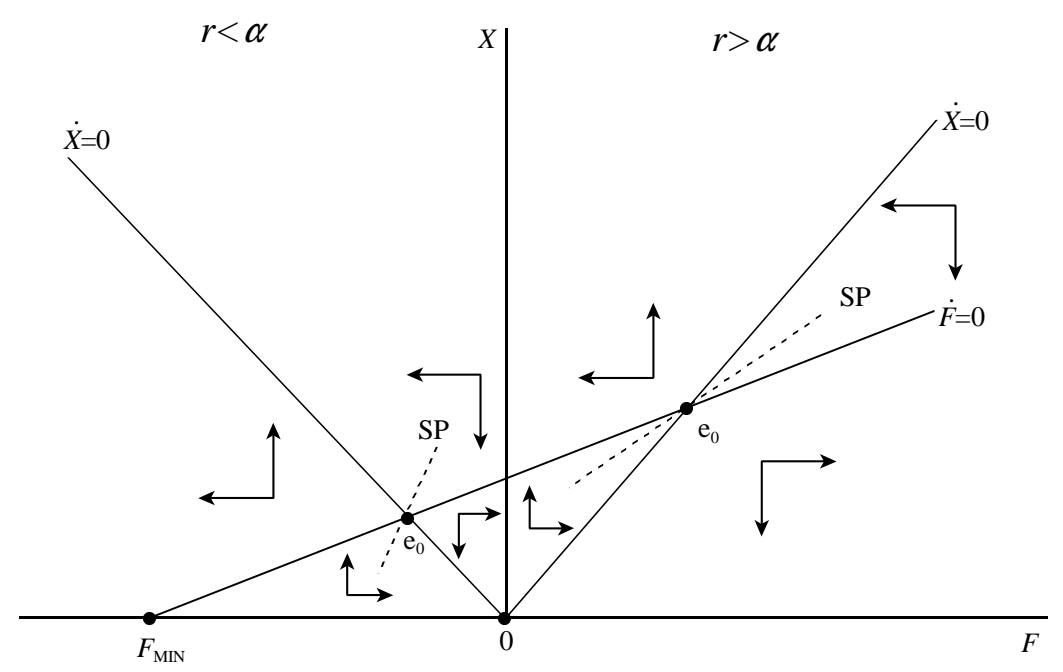

Figure 1: Phase diagram

The derivation of the $\dot{F}=0$ line is slightly more complicated as it depends on the trade balance which in turn depends on domestic supply and demand conditions and on exports. In the Appendix we show that, by using (T1.3)-(T1.9) in Table 1, the trade balance can be written as $T B=T B\left(X, t_{M}, s_{P}\right)$ with partial derivatives $\partial T B / \partial X<0, \partial T B / \partial t_{M}>0$, and $\partial T B / \partial s_{P}>0$. The intuition behind these partial equilibrium effects is as follows. First, an increase in full expenditure $X$ reduces labour supply and real domestic output, increases the terms of trade, reduces export earnings and increases imports. As a result, the trade balance deteriorates. Second, an increase in the tariff $t_{M}$ directly reduces imports and improves the trade balance. Finally, an increase in the product subsidy $s_{P}$ raises labour supply and real domestic output, decreases the terms of trade, increases export earnings and thus improves the trade balance. Since $\partial T B / \partial X<0$, it follows from (T1.2) that the $\dot{F}=0$ line is upward sloping. Points above (below) the $\dot{F}=0$ line are associated with a current account deficit (surplus) as has been indicated with horizontal arrows in Figure 1.

It follows from the arrow configuration in Figure 1 (and from the derivations in the Appendix) that the model is saddle-point stable for both cases under consideration-see the equilibria labeled $e_{0}$ in the two panels. For the creditor (debtor) nation steady-state net foreign assets are positive (negative). In both cases the saddle path is upward sloping-see the dashed curves labeled SP.

\section{Macroeconomic effects of a tariff}

In this section we briefly study the macroeconomic effects of an unanticipated and permanent increase of the import tariff. We assume that no debt policy is used and that the tariff revenue is rebated in a lump-sum fashion to households. We illustrate the impact, transitional, and 


\section{Table 2: Summary of qualitative results}

$$
\begin{aligned}
& \begin{array}{lllllllll}
X & F & T B & P & W / P & Y / P & L & C & Z
\end{array} \\
& \text { (a) Creditor nation }(r>\alpha)
\end{aligned}
$$

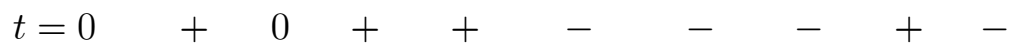

$$
\begin{aligned}
& t \rightarrow \infty \quad++\quad+\quad-\quad++\quad--\quad--\quad--\quad++ \text { ? } \\
& \text { (b) Debtor nation }(r<\alpha) \\
& \begin{array}{lllllllllllll}
t=0 & ++ & 0 & - & + & - & - & - & - & - & ++
\end{array}
\end{aligned}
$$

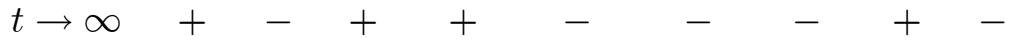

$$
\begin{aligned}
& \text { (c) Pure efficiency effects ( } r=\alpha \text { or egalitarian bond policy) } \\
& \forall t \geq 0 \quad+\quad \begin{array}{llllllllllll} 
& 0 & 0 & + & - & - & - & +
\end{array}
\end{aligned}
$$

Note:

$(+)+$ : (strong) positive effect; $(-)-$ : (strong) negative effect; 0: no effect; ?: ambiguous effect. The results in this table assume that labour supply is endogenous $(0<\gamma<1)$ and the diversity effect is operative $(\eta>1)$.

long-run effects with the aid of Figure 2 and summarize the results for convenience in Table 2. The mathematical derivations are found in the Appendix.

In terms of Figure 2, the increase in the tariff rotates the $\dot{F}=0$ line in a counter-clockwise direction and leaves the position of the $\dot{X}=0$ line unchanged. It follows from the diagram that in both cases the steady state changes from point $\mathrm{e}_{0}$ to $\mathrm{e}_{1}$ and full expenditure rises. Intuitively, the increase in full expenditure is made possible because the country uses the tariff to exploits its national market power. Net foreign assets rise (fall) for the creditor (debtor) nation. For both cases, the increase in full expenditure gives rise to a fall in labour supply, real output and wages and an increase in the terms of trade and domestic consumption. The effect on imports is negative for the debtor nation but ambiguous for the creditor nation. ${ }^{10}$ The long-run effects have been summarized in panels (a) and (b) of Table 2 in the rows labeled ' $t \rightarrow \infty$ '.

In the impact period, net foreign assets are predetermined and full expenditure jumps to the saddle path-see the move from $\mathrm{e}_{0}$ to $\mathrm{e}^{\prime}$ in the two panels of Figure 2. In both cases full expenditure rises so that employment, real output and wages fall and domestic consumption rises-see the rows labeled ' $t=0$ ' in Table 2 . The impact response of the trade balance, however, differs between the two cases. For the creditor nation the jump in full expenditure

\footnotetext{
${ }^{10}$ Tariff-inclusive spending on imports rises in both cases (see (T1.6)). The ambiguity arises in the case of the creditor nation because the rise in full expenditure is large and may well dominate the effect of the tariff.
} 


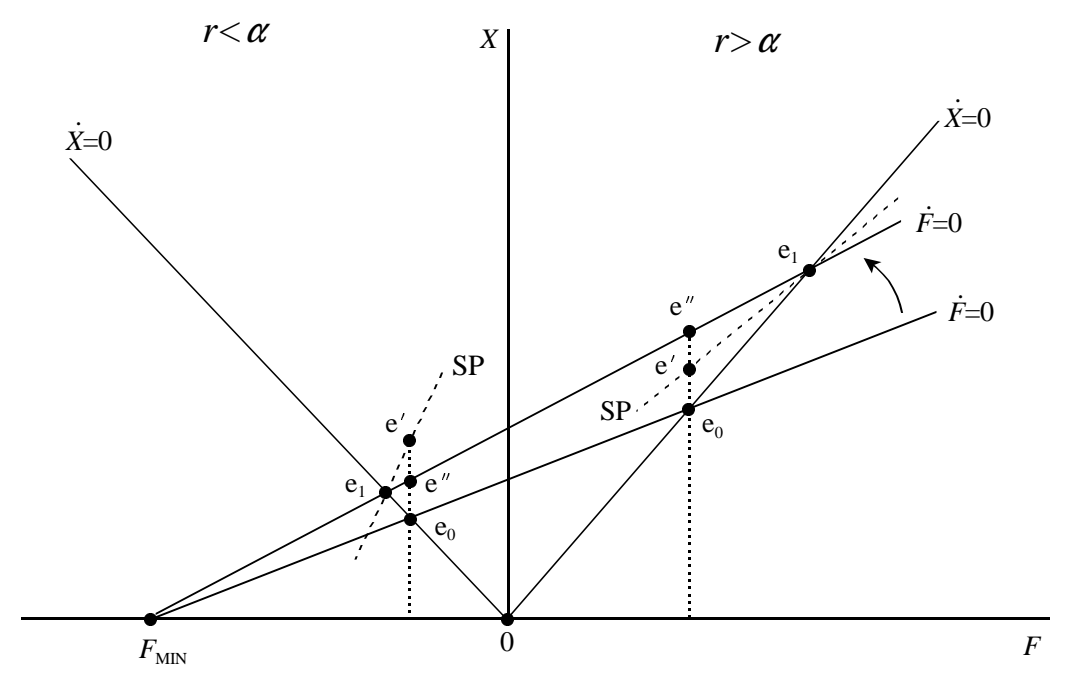

Figure 2: The effects of a tariff increase

is relative small so that the positive effect of the tariff shock dominates and the trade balance improves on impact, i.e. point $\mathrm{e}^{\prime}$ in the right-hand panel of Figure 2 is associated with a rising profile of net foreign assets $(\dot{F}(0)>0)$. Over time, the economy moves along the saddle path from $\mathrm{e}^{\prime}$ to $\mathrm{e}_{1}$. The long-run effect on full expenditure exceeds the short-run effect because the patient residents of the creditor nation accumulate additional net foreign assets during transition so that, over time, the trade balance can deteriorate and full expenditure can rise beyond its impact increase.

The adjustment path for the debtor nation is quite different. The increase in full expenditure at impact is large and dominates the tariff effect so that the trade balance deteriorates at impact and net foreign assets start to fall, i.e. $\dot{F}(0)<0$ in point $\mathrm{e}^{\prime}$ in the left-hand panel of Figure 2. During transition, the economy moves from $\mathrm{e}^{\prime}$ to $\mathrm{e}_{1}$ along the saddle path. Full expenditure overshoots its long-run equilibrium level at impact. Intuitively, the debtor country is populated by impatient agents who react to the tariff shock by borrowing more from abroad. Over time interest payments abroad rise and the trade balance must improve, i.e. full expenditure must fall.

\section{Welfare effects of a tariff}

This section explores the welfare properties of the model. In the most general version of our model, a change in the tariff has both efficiency and intergenerational redistributional effects. In order to disentangle these two effects, the first subsection studies the knife-edge case for which only the efficiency effects are operative. The next three subsections then deal with the general model, first without and then with bond policy. 


\subsection{Pure efficiency effects}

In the knife-edge case, for which the rate of interest exactly equals the rate of time preference $(r=\alpha)$, the model is essentially static as households neither save nor dissave. Households do not use the current account to smooth consumption $(F(t)=0, \forall t)$, and all generations have the same level of (human) wealth, full expenditure, and lifetime utility $(X(v, t)=X(t)=$ $(\alpha+\beta) H(t)$ and $\Lambda(v, t)=\Lambda, \forall t)$. Despite the fact that there are overlapping generations of finitely-lived agents, all households are essentially identical. Apart from their date of birth (and thus their age) there is no difference between generations. This property of the knifeedge case is attractive because it allows us to conduct a standard welfare analysis in which a fictional social planner maximizes the lifetime utility of the representative household.

The social planner treats all generations the same and thus-like the households-has no reason to use the current account. Suppressing the (now superfluous) time index, the planner chooses $C, Z, L$, and $P$ in order to maximize lifetime utility of the representative generation:

$$
(\alpha+\beta) \Lambda \equiv \gamma \delta \log C+\gamma(1-\delta) \log Z+(1-\gamma) \log [1-L]
$$

subject to, respectively, the resource constraint ${ }^{11}$ and the zero-trade-balance constraint:

$$
\begin{aligned}
\Omega_{0} L^{\eta} & =C+E_{0} P^{-\sigma_{T}}, \\
Z & =E_{0} P^{1-\sigma_{T}} .
\end{aligned}
$$

Straightforward manipulations yield the first-order conditions for the social optimum:

$$
\begin{aligned}
\frac{(1-\gamma) /(1-L)}{\gamma \delta / C} & =\eta \Omega_{0} L^{\eta-1} \\
\frac{(1-\delta) / Z}{\delta / C} & =\frac{1}{P}\left(\frac{\sigma_{T}}{\sigma_{T}-1}\right) .
\end{aligned}
$$

According to (21a) the marginal rate of substitution between leisure and consumption should be equated to the marginal product of labour. Equation (21b) says that the marginal rate of substitution between imports and domestic goods should be equated to the relative price of import goods $(1 / P)$ corrected for the international markup $\left(\sigma_{T} /\left(\sigma_{T}-1\right)\right)$.

\footnotetext{
${ }^{11}$ Equation (20a) is the resource constraint in the so-called constrained social optimum (CSO) when the planner cannot influence the size of individual firms because lump-sum taxes/transfers at the firm level are deemed to be absent (see Dixit and Stiglitz (1977)) Since we assume, however, that $\eta$ parameterizes both the diversity effect and the monopoly markup the CSO coincides with the unconstrained social optimum. (see Broer and Heijdra (2000) for a related result in a closed economy).
} 
For the decentralized market solution, the corresponding first-order conditions are: ${ }^{12}$

$$
\begin{aligned}
\frac{(1-\gamma) /(1-L)}{\gamma \delta / C} & =\left(\frac{1+s_{P}}{\eta}\right) \eta \Omega_{0} L^{\eta-1}[\equiv W / P], \\
\frac{(1-\delta) / Z}{\delta / C} & =\frac{1+t_{M}}{P} .
\end{aligned}
$$

By matching, respectively, (21a) with (22a) and (21b) with (22b) we derive that the decentralized market equilibrium replicates the social optimum for the following values of the tariff and product subsidy:

$$
1+s_{P}^{F}=\eta, \quad 1+t_{M}^{F}=\left(\frac{\sigma_{T}}{\sigma_{T}-1}\right)
$$

where the superscript ' $F$ ' stands for first-best. The first-best is an application-in the setting of monopolistic competition-of the so-called Bhagwati-Johnson principle of targeting (Dixit, 1985, p. 335). This principle says that a distortion is best countered by the instrument acting directly on the relevant margin. In the present model, the product subsidy restores productive efficiency and the tariff exploits national trade power.

The model thus incorporates both a domestic distortion, in the form of a monopolistically competitive production structure, and an international distortion, in the form of national market power. If the product subsidy, rather than being chosen optimally, is exogenously given, then the tariff will act on both distortions so that the welfare effect of a tariff increase is complicated by second-best considerations, precisely because $s_{P}$ may be sub-optimal itself. In Bettendorf and Heijdra (2000) we show that the welfare effect of a marginal change in the tariff can be written as follows:

$$
(\alpha+\beta) d \Lambda=\left(\frac{\gamma(1-\delta)}{1+\delta t_{M}}\right) \Phi_{M}\left(t_{M}, s_{P}\right)\left(\frac{d t_{M}}{1+t_{M}}\right)
$$

where $\Phi_{M}\left(t_{M}, s_{P}\right)$ is a complicated function of the structural parameters and the pre-existing tariff and product subsidy:

$$
\begin{aligned}
\Phi_{M}\left(t_{M}, s_{P}\right) \equiv & -\left[\delta+\frac{(1-\gamma)(1-\delta) \eta}{(1-\gamma)\left(1+t_{M}\right)+\gamma\left(1+s_{P}\right)\left(1+\delta t_{M}\right)}\right]\left(\frac{t_{M}-t_{M}^{F}}{1+t_{M}^{F}}\right) \\
& +\left[\frac{(1-\gamma)\left(1+\delta t_{M}\right)}{(1-\gamma)\left(1+t_{M}\right)+\gamma\left(1+s_{P}\right)\left(1+\delta t_{M}\right)}\right]\left(s_{P}-s_{P}^{F}\right) .
\end{aligned}
$$

The interpretation of these results is as follows. First, and rather obviously, if labour supply is exogenous $(\gamma=1)$ then output is fixed and independent of the product subsidy. As a result $s_{P}$ drops out of $\Phi_{M}$ altogether and it follows from (24)-(25) that the marginal lifetime utility

\footnotetext{
${ }^{12}$ Equation (22a) is a rewritten version of the markup pricing rule and is derived as follows. First, by using $P=\bar{P} N^{1-\eta}$ in the pricing rule $\left((15)\right.$ with $P_{i}=\bar{P}$ imposed) we get $W / P=\left[\left(1+s_{P}\right) /(\eta k)\right] N^{\eta-1}$. We also know that $N=[(\eta-1) /(\eta f)] L$ (see footnote 9$)$ so that $W / P$ can be rewritten as in (22a). Equation (22b) is obtained by combining (T1.5) and (T1.6).
} 
of a tariff is positive (negative) if the initial tariff falls short of (exceeds) the first-best optimal tariff $t_{M}^{F}$.

Second, and more interestingly, if labour supply is endogenous $(0<\gamma<1)$ then the pre-existing product subsidy affects $\Phi_{M}$ directly as is shown in (25). ${ }^{13}$ An implicit expression for the second-best optimal tariff, $t_{M}^{S}$, is obtained by setting $\Phi_{M}=0$ and solving for $t_{M}$ :

$$
\frac{t_{M}^{S}-t_{M}^{F}}{1+t_{M}^{F}}=\left[\frac{1-\gamma}{1-\gamma+\gamma \delta\left(1+s_{P}\right)+(1-\gamma)(\eta-1)\left(\frac{1-\delta}{1+\delta t_{M}^{S}}\right)}\right]\left(s_{P}-s_{P}^{F}\right) .
$$

Intuitively, if the pre-existing industrial policy is too ambitious-in the sense that $s_{P}>s_{P}^{F}-$ then domestic production is stimulated too much and the second-best tariff is higher than its first-best value because it is aimed at correcting the twin distortions of national market power and excessive domestic production. At the other extreme, if a country in which diversity effects are present does not subsidize production $\left(s_{P}=0\right.$ and $\left.s_{P}^{F}>0\right)$, then the second-best tariff is lower than its first-best value because it must in this case act as a (suboptimal) substitute for the absent industrial policy.

\subsection{Intergenerational welfare effects}

In the general version of our model, for which the interest rate may exceed (creditor country) or fall short of (debtor country) the rate of time preference, a marginal change in the tariff causes both efficiency and redistribution effects. As a result, the welfare analysis is more complicated than it was for the knife-edge case because it is necessary to keep track of the generational index. Indeed, the welfare effect on generations that already exist at the time of the shock $(t=0)$ is denoted by $d \Lambda(v, 0)$ for $v \leq 0$. In contrast, future generations' welfare effect is evaluated at birth, i.e. the relevant indicator is $d \Lambda(t, t)$ for $t>0$.

In order to link the allocation effects of the previous section to the welfare effects in this section, the cost-of-living index, $P_{U}(\tau)$, is used to relate sub-utility to full expenditure, $U(v, \tau)=X(v, \tau) / P_{U}(\tau)$, so that $(1)$ can be written as:

$$
\Lambda(v, t) \equiv \int_{t}^{\infty}\left[\log X(v, \tau)-\log P_{U}(\tau)\right] \mathrm{e}^{(\alpha+\beta)(t-\tau)} d \tau,
$$

where $P_{U}(\tau)$ is the cost-of-living index:

$$
P_{U}(\tau) \equiv\left(\frac{P(\tau)}{\gamma \delta}\right)^{\gamma \delta}\left(\frac{1+t_{M}}{\gamma(1-\delta)}\right)^{\gamma(1-\delta)}\left(\frac{W(\tau)}{1-\gamma}\right)^{1-\gamma}
$$

By using (8) and (27), the change in lifetime utility, $d \Lambda(v, t)$, can be (approximately) decomposed into a term due to a change in full expenditure and a change in the cost-of-living

\footnotetext{
${ }^{13}$ An increase in the product subsidy boosts full expenditure, employment, and real output and wages, and leads to a reduction in the terms of trade. See Bettendorf and Heijdra (2000).
} 
index:

$$
(\alpha+\beta) d \Lambda(v, t)=\tilde{X}(v, t)-(\alpha+\beta) \int_{t}^{\infty} \tilde{P}_{U}(\tau) \mathrm{e}^{(\alpha+\beta)(t-\tau)} d \tau
$$

where $\tilde{X}(v, t) \equiv d X(v, t) / X(v, t)$ and $\tilde{P}_{U}(\tau) \equiv d P_{U}(\tau) / P_{U}$. This decomposition is useful to explain the intuition behind the welfare effect on different generations.

Armed with the welfare indicator (29) we are now in a position to study the intergenerational welfare effects of a tariff. To bring out the main issues clearly, we first study the case where no debt policy is used $(B(t)=0, \forall t \geq 0)$. For existing generations $(v \leq 0)$ the welfare effect is obtained by setting $t=0$ in (29) and the only generation-specific term is the impact jump in full expenditure, $\tilde{X}(v, 0)$. The increase in the tariff gives rise to additional lump-sum transfers. Since all generations have the same expected remaining lifetime the present value of these additional transfers is the same for all generations. This implies that all existing generations enjoy the same effect on human wealth and thus, on that account, increase their full consumption by the same absolute amount, i.e. $d X(v, 0)=d X(0)>0 .{ }^{14}$ In a creditor country $(r>\alpha)$, old generations are much wealthier than young generations, so that the proportional change in full expenditure is much larger for the latter generations, i.e. $\partial \tilde{X}(v, 0) / \partial v>0$ and thus $\partial d \Lambda(v, 0) / \partial v>0$ and $d \Lambda(-\infty, 0)<d \Lambda(0,0)$.

In stark contrast, in a creditor country $(r<\alpha)$, agents follow a downward sloping time profile of full expenditure (see (8)) and young generations are much wealthier than old generations. As a result, $\partial \tilde{X}(v, 0) / \partial v<0, \partial d \Lambda(v, 0) / \partial v<0$ and $d \Lambda(-\infty, 0)>d \Lambda(0,0)$. Indeed, since extremely old generations have almost no net wealth (so that $\lim _{v \rightarrow-\infty} X(v, 0)=0$ ) the additional transfers give rise to a large change in welfare, i.e. $\lim _{v \rightarrow-\infty} d \Lambda(v, 0)=+\infty$. For convenience we summarize the findings up to this point in parts (i)-(ii) of Proposition 1.

Whilst it is thus possible to give a relative ranking of the effects on the different generations, it is not possible to determine analytically the absolute effects on the generations. The reason for this ambiguity can be clarified by studying the component parts that make up the total welfare effect. The sign of the full expenditure jump is unambiguously positive $(\tilde{X}(v, 0)>0)$. The cost-of-living effect experienced by current generations can be written as a weighted average of the initial and long-run effect on the cost-of-living index:

$$
(\alpha+\beta) \int_{0}^{\infty} \tilde{P}_{U}(\tau) \mathrm{e}^{(\alpha+\beta)(t-\tau)} d \tau \equiv \frac{(\alpha+\beta) \tilde{P}_{U}(0)+\lambda_{1} \tilde{P}_{U}(\infty)}{\alpha+\beta+\lambda_{1}} \gtreqless 0 .
$$

The ambiguity of the sign of the cost-of-living term is obvious in view of the fact that both $\tilde{P}_{U}(0)$ and $\tilde{P}_{U}(\infty)$ are ambiguous. As can be seen from Table 2 and equation (28), there is upward pressure on $P_{U}$ because both $P$ and $t_{M}$ rise but this effect may be offset by the change in $W$ which is ambiguous in general. ${ }^{15}$

\footnotetext{
${ }^{14}$ It follows from footnote 7 that $d X(0)=(\alpha+\beta) d H(0)$ and $d X(v, 0)=(\alpha+\beta) d H(0)$, where we have used the fact that in the absence of bond policy $d A(0)=d F(0)=0$ and $d A(v, 0)=d F(v, 0)=0$.

${ }^{15}$ There are two special cases for which more can be said about the terms appearing in (30). First, and rather
} 
The absolute welfare effect on existing generations is difficult to sign unambiguously due to the fact that the different components are either ambiguous or work in different directions from each other. It is possible, however, to determine a relative ranking of the welfare effects on present and future generations. Future generations are born in a world that is different from the initial steady state as a result of the shock. Their welfare change is obtained by substituting $v=t>0$ in equation (29). It is shown in Bettendorf and Heijdra (2000) that this welfare indicator can be written as a weighted average of the effect on a newborn, $d \Lambda(0,0)$ (that was discussed above) and the effect on a generation born in the new steady state, $d \Lambda(\infty, \infty)$ :

$$
d \Lambda(t, t)=e^{-\lambda_{1} t} d \Lambda(0,0)+\left[1-e^{-\lambda_{1} t}\right] d \Lambda(\infty, \infty),
$$

where $d \Lambda(\infty, \infty)$ is given by:

$$
(\alpha+\beta) d \Lambda(\infty, \infty)=\tilde{X}(\infty)-\tilde{P}_{U}(\infty)
$$

It is shown in Bettendorf and Heijdra (2000) that for a creditor nation $(r>\alpha)$, the generations born in the new steady-state are better off than very old generations, i.e. $d \Lambda(-\infty, 0)<$ $d \Lambda(\infty, \infty)$. The reason is that the former generations experience a higher full expenditure level $(\tilde{X}(\infty)>\tilde{X}(0))$ which is not offset by cost-of-living changes. In contrast, for a debtor nation steady-state generations are worse off than old generations, $d \Lambda(-\infty, 0)>d \Lambda(\infty, \infty)$, because the latter experience huge welfare gains as a result of the tariff shock (see above). The main results have been summarised in part (iii) of Proposition 1.

Proposition 1 A marginal increase in the tariff gives rise to the following welfare effects. (i) In a creditor country $(r>\alpha)$, the change in welfare of an existing generation depends negatively on its age $(-v)$, i.e. $d \Lambda(-\infty, 0)<d \Lambda(0,0)$; (ii) In a debtor country $(r<\alpha)$, the reverse holds, i.e. $d \Lambda(-\infty, 0)>d \Lambda(0,0)$. Furthermore, $\lim _{v \rightarrow-\infty} d \Lambda(v, 0)=+\infty$; (iii) In a creditor (debtor) country, old existing generations gain less (more) than future steady-state generations, i.e. $d \Lambda(-\infty, 0)<(>) d \Lambda(\infty, \infty)$

Proof: See text and Bettendorf and Heijdra (2000).

\subsection{Some numerical illustrations}

We now further illustrate Proposition 1 with the aid of some numerical simulations with a plausibly calibrated version of the model. Since we wish to study the effects on the intergenerational distribution of the initial tariff $\left(t_{M}\right)$ and the strength of the preference for diversity effect (as summarized by $\eta$ ), the model is calibrated in such a way that these parameters can

trivially, if labour supply is exogenous $(\gamma=1)$ then $W$ drops out of (28). Second, and more importantly, if labour supply is endogenous but the diversity effect is absent $(\eta=1)$ then the real wage $(W / P)$ is constant. In both cases $\tilde{P}_{U}(t)>0$ for all $t$ and the $\operatorname{sign}$ in $(30)$ is positive. 
be freely varied. The structural parameters that are held fixed throughout the simulations in Tables 3 and 4 are the rate of pure time preference $(\alpha=0.03)$, the birth rate $(\beta=0.06)$, and the elasticity of aggregate export demand $\left(\sigma_{T}=11\right)$. The pre-existing product subsidy is thirty percent $\left(s_{P}=0.3\right)$, the initial leisure-labour ratio is two $\left(\omega_{L L} \equiv(1-L) / L=2\right)$, and the output share of exports is twenty percent $\left(\omega_{X} \equiv E_{0} P^{1-\sigma_{T}}=0.2\right)$. In Table 3 we study a creditor nation which receives a ten percent output share of interest income from abroad $\left(\omega_{F} \equiv r F / Y=0.1\right)$. In Table 4 we examine a debtor nation whose interest payments to abroad amount to ten percent of aggregate output $\left(\omega_{F}=-0.1\right) .{ }^{16}$

\section{Table 3: Intergenerational distribution in the creditor country}

\begin{tabular}{lrrrrr} 
& & $\eta=1$ & $\eta=1.15$ & $\eta=1.3$ & $\eta=1.45$ \\
$t_{M}=0$ & $d \Lambda$ & 0.239 & 0.158 & 0.075 & -0.008 \\
& $d \Lambda(-\infty, 0)$ & -2.073 & -1.897 & -1.718 & -1.534 \\
& $d \Lambda(0,0)$ & 0.294 & 0.209 & 0.122 & 0.034 \\
& $d \Lambda(\infty, \infty)$ & 0.325 & 0.228 & 0.132 & 0.035 \\
$t_{M}=0.05$ & $\sigma(\%)$ & 84.5 & 77.0 & 62.0 & 26.3 \\
& $d \Lambda$ & 0.202 & 0.121 & 0.038 & -0.047 \\
& $d \Lambda(-\infty, 0)$ & -2.109 & -1.934 & -1.755 & -1.573 \\
& $d \Lambda(0,0)$ & 0.257 & 0.171 & 0.084 & -0.005 \\
& $d \Lambda(\infty, \infty)$ & 0.289 & 0.191 & 0.094 & -0.004 \\
$t_{M}=0.10$ & $\sigma(\%)$ & 80.3 & 69.9 & 48.3 & 0 \\
& $d \Lambda(-\infty, 0)$ & -2.146 & -1.971 & -1.793 & -1.611 \\
& $d \Lambda(0,0)$ & 0.220 & 0.134 & 0.046 & -0.044 \\
& $d \Lambda(\infty, \infty)$ & 0.253 & 0.155 & 0.057 & -0.042 \\
& $\sigma(\%)$ & 75.0 & 60.7 & 30.2 & 0 \\
$t_{M}=0.15$ & $d \Lambda$ & 0.130 & 0.047 & -0.037 & -0.123 \\
& $d \Lambda(-\infty, 0)$ & -2.182 & -2.008 & -1.830 & -1.649 \\
& $d \Lambda(0,0)$ & 0.184 & 0.097 & 0.008 & -0.082 \\
& $d \Lambda(\infty, \infty)$ & 0.218 & 0.119 & 0.020 & -0.080 \\
& $\sigma(\%)$ & 68.4 & 49.0 & 6.3 & 0 \\
$t_{M}^{M}$ & & 0.251 & 0.146 & 0.045 & -0.053 \\
\hline & & & & &
\end{tabular}

Parameter values are $\alpha=0.03, \beta=0.06, \sigma_{T}=11, s_{P}=0.3, \omega_{L L} \equiv(1-L) / L=2$, $\omega_{F} \equiv r F / Y=0.1, \omega_{X} \equiv E_{0} P^{1-\sigma_{T}} / Y=0.2 . \sigma(\%)$ is the percentage of the population (alive at the time of the shock) that does not lose as a result of a marginal increase in the tariff. $t_{M}^{M}$ is such that $\sigma(\%)=0.5$.

\footnotetext{
${ }^{16}$ The world interest rate $(r)$, the productivity index $\left(\Omega_{0}\right)$, the exogenous component of exports $\left(E_{0}\right)$, and the utility parameters $\left(\gamma\right.$ and $\delta$ ) are used as calibration parameters. For given values of $t_{M}$ and $\eta$ it is then possible to compute all relevant remaining information. Note that $\Omega_{0}$ and $E_{0}$ are used to ensure that $Y=P=1$ in the initial steady state.
} 
Table 3 and 4 present a number of welfare indicators for different combinations of $t_{M}$ (in the rows) and $\eta$ (in the columns). Consider the entry in Table 3 for $t_{M}=0$ and $\eta=1$. The intergenerational distribution of welfare is very uneven. Very old existing agents lose substantially $(d \Lambda(-\infty, 0)<0)$ but newborns at the time of the shock as well as all future generations gain unambiguously $(d \Lambda(0,0)>0$ and $d \Lambda(\infty, \infty)>0$, so that (31) shows that $d \Lambda(t, t)>0$ for all $t \geq 0)$. This pattern is preserved for all values of $t_{M}$ considered provided the diversity effect is not too high $(\eta \leq 1.3$, see the first three columns of Table 3 ).

Table 4: Intergenerational distribution in the debtor country

\begin{tabular}{lrrrrr} 
& & $\eta=1$ & $\eta=1.15$ & $\eta=1.3$ & $\eta=1.45$ \\
$t_{M}=0$ & $d \Lambda$ & 0.098 & 0.063 & 0.030 & -0.003 \\
& $d \Lambda(-\infty, 0)$ & $+\infty$ & $+\infty$ & $+\infty$ & $+\infty$ \\
& $d \Lambda(0,0)$ & 0.076 & 0.043 & 0.011 & -0.020 \\
& $d \Lambda(\infty, \infty)$ & 0.066 & 0.038 & 0.010 & -0.018 \\
& $\sigma(\%)$ & 100 & 100 & 100 & 72.6 \\
$t_{M}=0.05$ & $d \Lambda$ & 0.083 & 0.049 & 0.015 & -0.018 \\
& $d \Lambda(-\infty, 0)$ & $+\infty$ & $+\infty$ & $+\infty$ & $+\infty$ \\
& $d \Lambda(0,0)$ & 0.061 & 0.028 & -0.004 & -0.035 \\
& $d \Lambda(\infty, \infty)$ & 0.052 & 0.023 & -0.005 & -0.034 \\
& $\sigma(\%)$ & 100 & 100 & 95.0 & 57.6 \\
$t_{M}=0.10$ & $d \Lambda$ & 0.069 & 0.034 & 0 & -0.033 \\
& $d \Lambda(-\infty, 0)$ & $+\infty$ & $+\infty$ & $+\infty$ & $+\infty$ \\
& $d \Lambda(0,0)$ & 0.047 & 0.014 & -0.019 & -0.050 \\
& $d \Lambda(\infty, \infty)$ & 0.037 & 0.008 & -0.020 & -0.049 \\
& $\sigma(\%)$ & 100 & 100 & 78.1 & 45.9 \\
$t_{M}=0.15$ & $d \Lambda$ & 0.054 & 0.019 & -0.015 & -0.048 \\
& $d \Lambda(-\infty, 0)$ & $+\infty$ & $+\infty$ & $+\infty$ & $+\infty$ \\
& $d \Lambda(0,0)$ & 0.032 & -0.001 & -0.033 & -0.065 \\
& $d \Lambda(\infty, \infty)$ & 0.022 & -0.006 & -0.035 & -0.064 \\
& $\sigma(\%)$ & 100 & 98.8 & 64.4 & 36.7 \\
$t_{M}^{M}$ & & 0.511 & 0.361 & 0.217 & 0.081 \\
\hline & & & & & \\
\hline & & & & &
\end{tabular}

Parameter values are as in Table 3 , except $\omega_{F} \equiv r F / Y=-0.1$.

Hence, the simulations demonstrate that, for a wide range of values of $\eta$ and $t_{M}$, very old generations lose whereas young generations gain as a result of an increase in the tariff. But how does the change in the import tariff affect the population alive at the time of the shock? In order to answer that question we compute $\sigma(\%)$, which represents the percentage of the population (alive at the time of the shock) which is no worse-off as a result of the tariff increase. This variable can be interpreted as the degree of political support that exists for the introduction (if $t_{M}=0$ initially) or marginal increase (if $t_{M}>0$ initially) of the tariff. 
Indeed, if $\sigma(\%)$ exceeds fifty percent one would expect the existing population to vote in favour of introducing (or increasing) the tariff.

The results in Table 3 show that the degree of political support is inversely related to both the diversity parameter and the initial tariff. For example, if $t_{M}=0$ initially, political support is well above fifty percent for $\eta \leq 1.3$ but is below fifty percent for larger values of $\eta$. Similarly, raising the initial value of $t_{M}$ drags down the welfare profile for all (present and future) generations and thus lowers political support. For example, if $t_{M}=0.05$ and $\eta=1.3$, there is not enough political support for a further increase in the tariff. Even though the young would gain from such a further increase, too many older generations would lose out in this case. This shows that, provided the diversity effect is sufficiently strong, the uneven intergenerational burden can make even the introduction of a tariff unattractive to existing generations.

Table 4 shows that in a debtor country political support is also inversely related to both the initial tariff and the diversity effect. In contrast to the creditor nation, however, political support tapers off only very slowly as $t_{M}$ or $\eta$ is raised. For example, even for the relatively high tariff/diversity combination of $t_{M}=0.15$ and $\eta=1.3$ almost two-thirds of the existing population would support a further increase in the tariff rate. The intuition is, of course, that the old existing generations benefit substantially from such a tariff increase (see Proposition 1).

\subsection{Egalitarian bond policy}

It is clear from the discussion up to point that the savings response by existing households at the time of the shock is responsible for the uneven distribution of welfare across generations. Indeed, in the creditor (debtor) nation existing households respond to the tariff shock by increasing (decreasing) their stock of net foreign assets. Since eventually the current account must be re-equilibrated, the higher (lower) stock of foreign assets is matched by a lower (higher) trade balance and a higher terms of trade. As a result, generations born in the new steady state face different economic conditions than the existing generations do (see Table 2).

If the policy maker accompanies the tariff shock with a suitably chosen bond policy then the intergenerational redistributional effects can be neutralized and the pure 'efficiency effects' of the import tariff can be brought to the fore. Figure 2 can be used to illustrate the form such an egalitarian bond policy should take. The key thing to note is that the tariff-cum-bond policy should neutralize the savings response at impact. This is done by using bond policy to shift the $\dot{X}=0$ line such that it intersects the new $\dot{F}=0$ line in points directly above the initial steady state, i.e. in points $\mathrm{e}^{\prime \prime}$ in the two panels. Hence, in the creditor (debtor) country intergenerational redistribution is neutralized by engineering a discrete increase (decrease) in public debt, i.e. $d B^{*}>0(<0)$ for $r>\alpha(r<\alpha)$ (see the Appendix for the exact expression for $\left.d B^{*}\right)$. 
The economy jumps from $\mathrm{e}_{0}$ to $\mathrm{e}^{\prime \prime}$ at impact and there is no further transition ${ }^{17}$ so that all future generations experience the same welfare effect $(d \Lambda(t, t)=d \Lambda$ for $t \geq 0)$. By setting the appropriate once-off age-specific transfer (for the creditor country) or levy (for the debtor country) it is possible to increase full expenditure by the same relative amount for all existing generations $(\tilde{X}(v, 0)=\tilde{X}$ for all $v \leq 0)$ so that these generations also experience the same welfare change $(d \Lambda(v, 0)=d \Lambda$ for $v \leq 0) .{ }^{18}$

The following result can be established for the egalitarian tariff-cum-bond policy.

Proposition 2 If the tariff increase is accompanied by a bond policy which eliminates all intergenerational redistributional effects (so that $d \Lambda(v, 0)=d \Lambda(t, t)=d \Lambda$ for all $v \leq 0$ and $t \geq 0)$, and the product subsidy is at its first-best level $\left(s_{P}=s_{P}^{F}\right)$ then $d \Lambda=0$ if the tariff is also set at its first-best level $\left(t_{M}=t_{M}^{F}\right)$.

Proof: See Bettendorf and Heijdra (2000).

Proposition 2 thus confirms that the first-best results-obtained for the knife-edge case in subsection 4.1-are still valid in the more general model. Indeed, the analysis so far suggests that the Bhagwati-Johnson principle of targeting is equally valid in an overlapping-generations setting. Whilst the product subsidy restores productive efficiency and the tariff exploits national market power, the bond policy eliminates the intergenerational externality. ${ }^{19}$

We now return to the simulations reported in Tables 3 and 4. Several conclusions can be drawn from these tables. First, the simulations confirm the second-best results discussed in subsection 4.1, i.e. if the pre-existing product subsidy is higher than its first-best value $\left(s_{P}>s_{P}^{F}\right)$ then the second-best optimal egalitarian tariff is also set higher than its first-best level $\left(t_{M}^{S}>t_{M}^{F}\right)$. Though we have been unable to prove this instrument complementarity analytically, it seems a robust feature of our model.

Second, the simulations suggest that public debt and the tariff are also complementary instruments. Consider, for example, the columns for $\eta=1.3$ in Tables 3 and 4 (for which value of $\eta$ the product subsidy is at its first-best level) and define a majoritarian tariff $\left(t_{M}^{M}\right)$ as that tariff rate which just demands a majority among existing generations at the pollls. It follows from the simulations that in a creditor (debtor) country, the non-use of bond policy causes the majoritarian tariff to be lower (higher) than its first-best level, i.e. $t_{M}^{M}<(>) t_{M}^{F}$. For example, in Table 3 in the column for $\eta=1.3, t_{M}^{M}=0.045$ and $t_{M}^{F}=0.1$ and, since $d B^{*}>0$ for the creditor country, creating debt allows for a more ambitious trade policy. In contrast, in a debtor nation the majoritarian tariff is too high and $d B^{*}<0$, i.e. by creating a public asset the tariff can be pushed to its optimal level.

\footnotetext{
${ }^{17}$ For convenience, panel (c) of Table 2 summarizes the qualitative effects on the macroeconomic variables.

${ }^{18}$ For the creditor (debtor) country the transfer (levy) increases with age.

${ }^{19}$ The nature of this intergenerational externality can be seen from Table 3 . In the case discussed there, present generations fail to support the first-best tariff/product subsidy $\operatorname{mix}\left(t_{M}=0.1\right.$ and $\left.s_{P}=0.3\right)$ at the polls because they cannot appropriate all the benefits of such a policy.
} 


\section{Conclusions}

A dynamic overlapping-generations model of a small open economy with monopolistic competition in the goods market is constructed and analyzed. Industrial policy in the form of an import tariff reduces real output and employment and improves the terms of trade both in the impact period and in the new steady state. An increase in the tariff has important intergenerational distribution effects. The prudent use of bond policy neutralizes these intergenerational inequities and suggests first-best and second-best optimal tariff rates. The first-best tariff exploits national market power, but the second-best tariff contains a correction to account for the existence of a potentially suboptimal product subsidy.

In future work we hope to construct a two-country version of our model, expanded with physical capital as a production factor, in which the optimal tariff issue can be studied both with and without international coordination. This would lead to a further clarification of the role of domestic and foreign scale economies and international market power on the one hand and the degree of physical capital mobility on the other. It would furthermore forge a link with the strategic trade policy literature mentioned in the introduction.

\section{Appendix}

In this appendix we derive the key results that are used in the text. Bettendorf and Heijdra (2000) contains more elaborate derivations and is available upon request.

\section{A.1 Derivation of the trade balance expression}

The construction of the phase diagram (Figure 1 in the text) proceeds as follows. First we use equations (T1.3), (T1.7) and (T1.8) to summarize labour market equilibrium (LME):

$$
f(L) \equiv z_{0}(1-L) L^{\eta-1}=x,
$$

where $x \equiv X / P$ is real full expenditure and $z_{0} \equiv\left(1+s_{P}\right) \Omega_{0} /(1-\gamma)$. It follows from (A.1) that $f(L)$ has the following derivative:

$$
f^{\prime}(L)=z_{0} L^{\eta-1}\left[(\eta-1)\left(\frac{1-L}{L}\right)-1\right] .
$$

We are interested in the properties of $f(L)$ in the economically meaningful interval $0 \leq L \leq 1$. Clearly, $f(1)=0, f(0)=z_{0}$ if $\eta=1$, and $f(0)=0$ if $\eta>1$. Finally, for $\eta=1, f(L)$ is downward sloping but for $\eta>1$ we have:

$$
f^{\prime}(L) \gtreqless 0 \Leftrightarrow L \lesseqgtr L_{\mathrm{MIN}} \equiv \frac{\eta-1}{\eta} .
$$

In summary, the function $f(L)$ is as drawn in the top panel in Figure A.1 (assuming $1<\eta<2$ so that $f^{\prime \prime}(L)<0$ for $L \geq 0$ ). If $\eta=1$, then $f(L)$ is the dashed line from $z_{0}$ to point d. 
If the diversity effect is operative $(\eta>1)$ then $f(L)$ is the solid line from the origin (point e) through a, c, and b to point d. For $L=L_{\mathrm{MIN}}, x$ reaches its maximum value ( $\left.x_{\mathrm{MAX}}\right)$ consistent with labour market equilibrium.

Now consider what happens if $x=x_{0}$. Both points a and $\mathrm{b}$ are consistent with labour market equilibrium. In the bottom panel of Figure A.1 labour demand and supply are depicted by, respectively, $L^{D}$ and $L^{S}\left(x_{0}\right)$ (supply depends on $x_{0}$ through the wealth effect). Labour demand slopes upward because of the diversity effect (see Devereux, Head, and Lapham (1996, p. 241)). It would appear that there are two suitable equilibria but it is shown below that the equilibrium associated with point a is unstable. Hence with an operative diversity effect the feasible range of labour market equilibria is $L \in\left(L_{\mathrm{MIN}}, 1\right]$ and thus $x \in\left[0, x_{\mathrm{MAX}}\right)$. In terms of Figure A.1 this amounts to selecting only the employment solution on the downward sloping segment of the $f(L)$ function. In terms of parameters used in the linearized model the feasible region for $L$ can be rewritten as:

$$
0 \leq(\eta-1) \omega_{L L}<1
$$

where $\omega_{L L} \equiv(1-L) / L$.

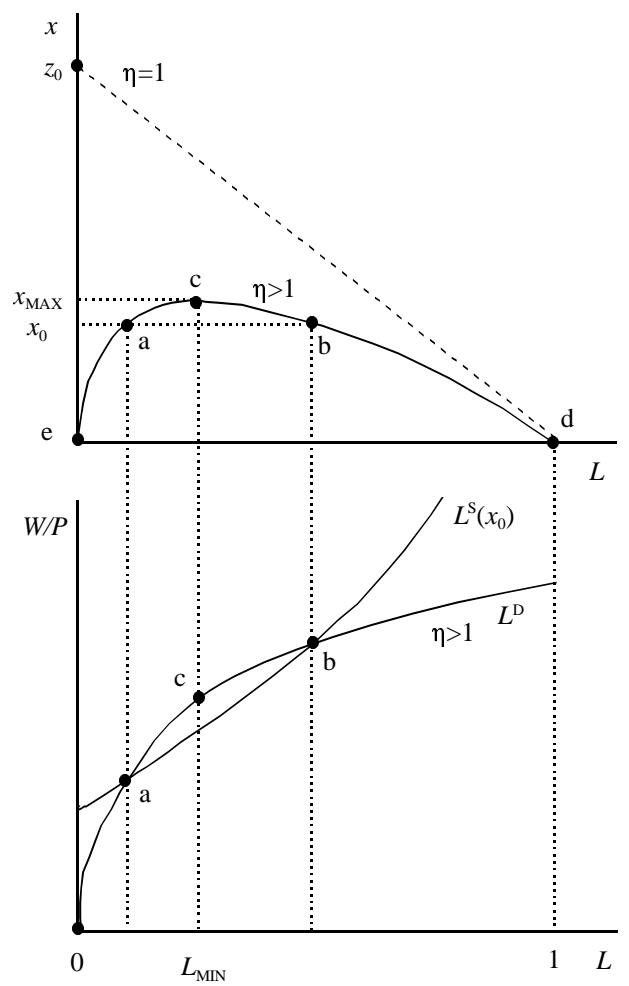

Figure A.1: Feasible labour market equilibria

The upshot of the discussion so far is that equilibrium employment can be expressed as a unique function of $x$ and $z_{0}$, i.e. $L=L\left(x, z_{0}\right)$ with $L_{x} \equiv \partial L / \partial x<0$ and $L_{z_{0}} \equiv \partial L / \partial z_{0}>0$. 
By substituting this relation in (T1.8) and also using (T1.4)-(T1.5) we get the expression for goods market equilibrium (GME):

$$
\Omega_{0} L\left(x, z_{0}\right)^{\eta}=\gamma \delta x+E_{0} P^{-\sigma_{T}}
$$

where the left-hand side is aggregate supply of domestic goods and the right-hand side is demand for domestic goods consisting of demand by residents plus demand by foreigners (exports). An increase in $x$ lowers supply, raises demand by residents and thus-to restore goods market equilibrium-exports must fall, i.e. $P$ must rise. Recalling that $x \equiv X / P$, this reasoning shows that the terms of trade can be written as a unique function of $X$ and $z_{0}$ :

$$
P=P\left(X, z_{0}\right)
$$

which has the following partial derivatives:

$$
\begin{aligned}
P_{X} & \equiv \frac{\partial P}{\partial X}=\frac{\Omega_{0} \eta L^{\eta-1} L_{x}-\gamma \delta}{x\left[\Omega_{0} \eta L^{\eta-1} L_{x}-\gamma \delta\right]-\sigma_{T} E_{0} P^{-\sigma_{T}}}>0 \\
P_{z_{0}} & \equiv \frac{\partial P}{\partial z_{0}}=\frac{\Omega_{0} P \eta L^{\eta-1} L_{z_{0}}}{x\left[\Omega_{0} \eta L^{\eta-1} L_{x}-\gamma \delta\right]-\sigma_{T} E_{0} P^{-\sigma_{T}}}<0
\end{aligned}
$$

Finally, by using (A.6) in combination with (T1.6) and (T1.9) we obtain the following expression for the trade balance:

$$
T B=T B\left(X, z_{0}, t_{M}\right)=E_{0} P\left(X, z_{0}\right)^{1-\sigma_{T}}-\left(\frac{\gamma(1-\delta)}{1+t_{M}}\right) X,
$$

with the following partial derivatives:

$$
\begin{aligned}
T B_{X} & \equiv \frac{\partial T B}{\partial X}=-\left(\sigma_{T}-1\right) E_{0} P^{-\sigma_{T}} P_{X}-\frac{\gamma(1-\delta)}{1+t_{M}}<0 \\
T B_{z_{0}} & \equiv \frac{\partial T B}{\partial z_{0}}=-\left(\sigma_{T}-1\right) E_{0} P^{-\sigma_{T}} P_{z_{0}}>0 \\
T B_{t_{M}} & \equiv \frac{\partial T B}{\partial t_{M}}=\frac{\gamma(1-\delta) X}{\left(1+t_{M}\right)^{2}}>0 .
\end{aligned}
$$

\section{A.2 Model solution}

We log-linearize the model of Table 1 around an initial steady state-see Table A.1 for the resulting expressions. We use the following notational conventions. A tilde $\left({ }^{(\sim)}\right)$ above a variable denotes its rate of change around the initial steady-state, e.g., $\tilde{X}(t) \equiv d X(t) / X$. A variable with a tilde and a dot is the time derivative expressed in terms of the initial steadystate, for example, $\dot{\tilde{X}}(t) \equiv \dot{X}(t) / X$. The only exceptions to that convention refer to the tariff, the various financial assets, and the trade balance: $\tilde{t}_{M} \equiv d t_{M} /\left(1+t_{M}\right), \tilde{B}(t) \equiv r d B(t) / Y$, $\dot{\tilde{B}}(t) \equiv r \dot{B}(t) / Y, \tilde{F}(t) \equiv r d F(t) / Y, \dot{\tilde{F}}(t) \equiv r \dot{F}(t) / Y$, and $\widetilde{T B}(t) \equiv d T B(t) / Y$.

The model can be reduced to a two-dimensional system of first-order differential equations in net foreign assets $(\tilde{F}(t)$, a predetermined variable) and full expenditure $(\tilde{X}(t)$, a nonpredetermined 'jump' variable). Conditional upon the state variables, the static part of the 
log-linearized model, consisting of equations (TA.3)-(TA.9) in Table A.1, can be used to derive the following 'quasi-reduced form' expressions:

$$
\begin{aligned}
\tilde{Y}(t)-\tilde{P}(t) & =\eta \tilde{L}(t)=-(\phi-1)[\tilde{X}(t)-\tilde{P}(t)], \\
\tilde{P}(t) & =(1-\zeta) \tilde{X}(t), \\
\widetilde{T B}(t) & =-\left(\zeta \phi+\omega_{F}\right) \tilde{X}(t)+\left(\omega_{F}+\omega_{X}\right) \tilde{t}_{M}, \\
\tilde{W}(t)-\tilde{P}(t) & =-\left(\frac{\eta-1}{\eta}\right)(\phi-1) \zeta \tilde{X}(t),
\end{aligned}
$$

where $\phi$ and $\zeta$ are composite parameters:

$$
\phi \equiv \frac{1+\omega_{L L}}{1+\omega_{L L}(1-\eta)}>1, \quad 0<\zeta \equiv \frac{\sigma_{T} \omega_{X}}{\phi+\omega_{X}\left(\sigma_{T}-1\right)}<1
$$

The sign of $\omega_{F}+\zeta \phi$ in (A.10c) is seen by rewriting it slightly and noting that $\omega_{F}+\omega_{X}>0$ :

$$
\omega_{F}+\zeta \phi=\omega_{F}+\omega_{X}+(1-\zeta)\left(\sigma_{T}-1\right) \omega_{X}>0
$$

Note that (A.10b) and (A.10c) are the log-linearized versions of, respectively, (A.6) and (A.8). Furthermore, the feasibility condition (A.4) holds iff the numerator of $\phi$ in (A.11) is positive.

\section{A.2.1 Stability}

By using (TA.1), (TA.2), and (A.10c) the dynamical system for net foreign assets and full expenditure is obtained:

$$
\left[\begin{array}{c}
\dot{\tilde{F}}(t) \\
\dot{\tilde{X}}(t)
\end{array}\right]=\Delta\left[\begin{array}{c}
\tilde{F}(t) \\
\tilde{X}(t)
\end{array}\right]+\left[\begin{array}{c}
r\left(\omega_{X}+\omega_{F}\right) \tilde{t}_{M} \\
-\left[(r-\alpha) / \omega_{F}\right] \tilde{B}
\end{array}\right]
$$

where the Jacobian matrix of coefficients on the right-hand side is:

$$
\Delta \equiv\left[\begin{array}{ll}
r & -r\left(\zeta \phi+\omega_{F}\right) \\
-(r-\alpha) / \omega_{F} & r-\alpha
\end{array}\right] .
$$

It follows from (A.13) that $|\Delta|=-r \zeta \phi\left[(r-\alpha) / \omega_{F}\right]<0$, where the inequality holds because $(r-\alpha) / \omega_{F}>0, \zeta>0$ and $\phi>1$. Since $|\Delta|=-\lambda_{1} \lambda_{2}<0$, it follows that the model is saddle-point stable and possesses one stable characteristic root $\left(-\lambda_{1}<0\right)$ and one unstable $\operatorname{root}\left(\lambda_{2}>r>0\right)$.

The proof of $\lambda_{2}>r$ proceeds as follows. The characteristic equation of $\Delta, g(\lambda) \equiv|\lambda I-\Delta|$, has two roots $\left(g\left(-\lambda_{1}\right)=g\left(\lambda_{2}\right)=0\right)$ and satisfies $g(0)=|\Delta|<0$ and $g^{\prime}\left(\lambda_{2}\right)>0$. It follows that $\lambda_{2}>r \Longleftrightarrow g(r)<0$. After some manipulation we get:

$$
g(r)=r^{2}-(2 r-\alpha) r-r \zeta \phi\left(\frac{r-\alpha}{\omega_{F}}\right)=-r\left(\frac{r-\alpha}{\omega_{F}}\right)\left(\omega_{F}+\zeta \phi\right)<0 .
$$


Table A.1: Log-Linearized Version of the Model

$$
\begin{aligned}
\dot{\tilde{X}}(t) & =(r-\alpha) \tilde{X}(t)-\left[(r-\alpha) / \omega_{F}\right][\tilde{F}(t)+\tilde{B}] \\
\dot{\tilde{F}}(t) & =r[\tilde{F}(t)+\widetilde{T B}(t)] \\
\tilde{L}(t) & =\tilde{Y}(t)-\tilde{W}(t) \\
\tilde{Y}(t)-\tilde{P}(t) & =\left(1-\omega_{X}\right) \tilde{C}(t)-\sigma_{T} \omega_{X} \tilde{P}(t) \\
\tilde{C}(t)+\tilde{P}(t) & =\tilde{X}(t) \\
\tilde{Z}(t) & =\tilde{X}(t)-\tilde{t}_{M} \\
\tilde{L}(t) & =\omega_{L L}[\tilde{W}(t)-\tilde{X}(t)] \\
\tilde{Y}(t)-\tilde{P}(t) & =\eta \tilde{L}(t) \\
\widetilde{T B}(t) & =-\left(\sigma_{T}-1\right) \omega_{X} \tilde{P}(t)-\left(\omega_{X}+\omega_{F}\right) \tilde{Z}(t)
\end{aligned}
$$

Shares:

$\omega_{L L} \equiv(1-L) / L$, leisure/work ratio.

$\omega_{F} \equiv r F / Y$, share of asset income in national income.

$\omega_{X} \equiv E_{0} P^{1-\sigma_{T}} / Y$, share of exports in national income.

Notes:

(a) We assume that $B=0$ initially.

(b) Relationship between shares: $\omega_{F}+\omega_{X}=Z / Y>0$.

\section{A.2.2 Long-run results}

By imposing the steady state in (A.12) we obtain the long-run results:

$$
\left[\begin{array}{c}
\tilde{F}(\infty) \\
\tilde{X}(\infty)
\end{array}\right] \equiv\left[\begin{array}{c}
\omega_{F} \\
1
\end{array}\right]\left(\frac{\omega_{F}+\omega_{X}}{\zeta \phi}\right) \tilde{t}_{M}-\left[\begin{array}{l}
\zeta \phi+\omega_{F} \\
1
\end{array}\right] \frac{\tilde{B}}{\zeta \phi}
$$

The long-run results for the other variables can be obtained by using the expression for $\tilde{X}(\infty)$ in (A.10a)-(A.10d).

\section{A.2.3 Impact effects and transitional dynamics}

At impact, the stock of net foreign assets is predetermined $(\tilde{F}(0)=0)$ and Judd's (1998) Laplace transform techniques furnish expressions for the jumps in the non-predetermined variables:

$$
\begin{aligned}
\tilde{X}(0) & =\left(\frac{r-\alpha}{\omega_{F} \lambda_{2}}\right)\left[\left(\frac{r\left(\omega_{F}+\omega_{X}\right)}{\lambda_{2}-r}\right) \tilde{t}_{M}+\tilde{B}\right] \\
& =\left(\frac{\omega_{F}+\omega_{X}}{\omega_{F}+\phi \zeta}\right) \tilde{t}_{M}+\left(\frac{r-\alpha}{\omega_{F} \lambda_{2}}\right)\left[\tilde{B}-\tilde{B}^{*}\right],
\end{aligned}
$$


where $\tilde{B}^{*}$ is defined as:

$$
\tilde{B}^{*} \equiv\left(\frac{\omega_{F}\left(\omega_{X}+\omega_{F}\right)}{\phi \zeta+\omega_{F}}\right) \tilde{t}_{M}
$$

As before, the impact results for the other variables can be obtained by using the expression for $\tilde{X}(0)$ in (A.10a)-(A.10d).

Since the shocks are unanticipated and permanent, the transition paths for all variables can be written as weighted averages of the respective impact and long-run effects with the time-varying weights depending on the amount of time that has elapsed following the shock. i.e. $\tilde{x}(t)=e^{-\lambda_{1} t} \tilde{x}(0)+\left[1-e^{-\lambda_{1} t}\right] \tilde{x}(\infty)$, where the adjustment speed is determined by the stable root, $-\lambda_{1}$. The results in section 3 and 4 of the text are based, respectively, on no bond policy $(\tilde{B}=0)$ and egalitarian bond policy $\left(\tilde{B}=\tilde{B}^{*}\right)$. For convenience, Table 2 in the text summarizes the qualitative results.

\section{References}

Bénassy, J. P. (1996). Taste for variety and optimum production patterns in monopolistic competition. Economics Letters, 52:41-47.

Bénassy, J. P. (1998). Is there always too little research in endogenous growth with expanding product variety? European Economic Review, 42:61-69.

Bettendorf, L. J. H. and Heijdra, B. J. (2000). Intergenerational welfare effects of a tariff under monopolistic competition: Mathematical appendix. Mimeo, University of Groningen. Download from: http://www.eco.rug.nl/medewerk/heijdra/download.htm.

Bettendorf, L. J. H. and Heijdra, B. J. (forthcoming). Intergenerational and international welfare leakages of a product subsidy in a small open economy. International Tax and Public Finance, ??:??-??

Bhagwati, J. N. (1967). Non-economic objectives and the efficiency properties of trade. Journal of Political Economy, 75:738-742.

Bhagwati, J. N. (1971). The generalized theory of distortions and welfare. In Bhagwati, J. et al., editors, Trade, Balance of Payments and Growth: Essays in Honor of Charles P. Kindleberger. North-Holland, Amsterdam.

Blanchard, O.-J. (1985). Debts, deficits, and finite horizons. Journal of Political Economy, 93:223-247.

Bovenberg, A. L. (1993). Investment promoting policies in open economies: The importance of intergenerational and international distributional effects. Journal of Public Economics, 51:3-54. 
Bovenberg, A. L. (1994). Capital taxation in the world economy. In Van der Ploeg, F., editor, Handbook of International Macroeconomics. Basil Blackwell, Oxford.

Bovenberg, A. L. and Heijdra, B. J. (1998). Environmental tax policy and intergenerational distribution. Journal of Public Economics, 67:1-24.

Brander, J. A. (1995). Strategic trade policy. In Grossman, G. M. and Rogoff, K., editors, Handbook of International Economics, volume III. Elsevier, Amsterdam.

Broer, D. P. and Heijdra, B. J. (forthcoming). The investment tax credit under monopolistic competition. Oxford Economic Papers, ??:???-???

Buiter, W. H. (1987). Fiscal policy in open, interdependent economies. In Razin, A. and Sadka, E., editors, Economic Policy in Theory and Practice. Macmillan, London.

Devereux, M. B., Head, A. C., and Lapham, B. J. (1996). Monopolistic competition, increasing returns, and the effects of government spending. Journal of Money, Credit, and Banking, 28:233-253.

Dixit, A. K. (1985). Tax policy in open economies. In Auerbach, A. J. and Feldstein, M., editors, Handbook of Public Economics, volume I. North-Holland, Amsterdam.

Dixit, A. K. and Stiglitz, J. E. (1977). Monopolistic competition and optimum product diversity. American Economic Review, 67:297-308.

Engel, C. and Kletzer, K. (1990). Tariffs and saving in a model with new generations. Journal of International Economics, 28:71-91.

Flam, H. and Helpman, E. (1987). Industrial policy under monopolistic competition. Journal of International Economics, 22:79-102.

Galor, O. (1994). Tariffs, income distribution and welfare in a small open overlappinggenerations economy. International Economic Review, 35:173-192.

Gavin, M. (1991). Tariffs and the current account: On the macroeconomics of commercial policy. Journal of Economic Dynamics and Control, 15:27-52.

Giovannini, A. (1988). The real exchange rate, the capital stock, and fiscal policy. European Economic Review, 32:1747-1767.

Gros, D. (1987). A note on the optimal tariff, retaliation and the welfare loss from tariff wars in a framework with intra-industry trade. Journal of International Economics, 23:357-367. 
Heijdra, B. J. (1998). Fiscal policy multipliers: The role of monopolistic competition, scale economies, and intertemporal substitution in labour supply. International Economic Review, 39:659-696.

Heijdra, B. J. and Van der Ploeg, F. (1996). Keynesian multipliers and the cost of public funds under monopolistic competition. Economic Journal, 106:1284-1296.

Johnson, H. G. (1965). Optimal trade intervention in the presence of domestic distortions. In Baldwin, R. et al., editors, Trade, Growth, and the Balance of Payments: Essays in Honor of Gottfried Haberler. North-Holland, Amsterdam.

Judd, K. L. (1998). Numerical Methods in Economics. MIT Press, Cambridge, MA.

Keuschnigg, C. and Kohler, W. (1996). Commercial policy and dynamic adjustment under monopolistic competition. Journal of International Economics, 40:373-409.

Kotlikoff, L. J. and Summers, L. H. (1987). Tax incidence. In Auerbach, A. J. and Feldstein, M., editors, Handbook of Public Economics, volume I. North-Holland, Amsterdam.

Krugman, P. R. (1990). Rethinking International Trade Theory. MIT Press, Cambridge, MA.

Sen, P. and Turnovsky, S. J. (1989). Tariffs, capital accumulation, and the current account in a small open economy. International Economic Review, 30:811-831.

Spence, M. (1976). Product selection, fixed costs, and monopolistic competition. Review of Economic Studies, 43:217-235. 